\title{
First seminar on International Red Cross emergency medical actions
}

The first seminar on International Red Cross emergency medical actions, jointly organized by the ICRC and the League of Red Cross Societies, took place in Geneva from 13 to 16 February 1981. Eighty-five doctors, nurses, nutritionists and health technicians, all of them with practical experience gained in several emergency field missions for the International Red Cross, took part in the seminar. They represented 23 National Societies.

\section{Specific character of Red Cross medical action}

Beside some important subjects discussed, the seminar gave special emphasis to the difference between Red Cross medical action and that of other organizations. It was noted that the Red Cross acted on the basis of its own special principles, such as neutrality, impartiality, non-discrimination, etc. This special characteristic often stood in the way of integration of the Red Cross with actions by other organizations-governmental or non-governmental-which operated under different rules. In the event of conflict, for example, the ICRC came to the aid of victims on both sides of the front without distinction, whereas other organizations acted only in one particular region or for victims chosen on the basis of their own criteria.

\section{Importance of criteria for action}

In medical programmes, as in all of its actions, the Red Cross must observe certain rules: it must act only in the interest of the victims; it must not create the need for a kind of medical service not adapted to local conditions; it must make sure that there was a certain balance between 
the aid given to victims and the conditions under which the general population lived, so as to avoid favouring the former in comparison to the latter. The Red Cross had also to take into consideration local resources in personnel and material in its planning, and use them first in its action. Red Cross teams had also to make certain that the largest possible number of patients benefited from their care, without giving privileges to some as compared to others.

It was also important to respect local traditions and the cultural heritage of the victims.

Finally, it had to be borne in mind that Red Cross medical programmes were limited to periods of emergency and that it was therefore advisable to use simple and rational techniques.

There was also reference in the discussions to external pressures which must be resisted. These were often expressions of public opinion and could lead to precipitate and uncontrolled action which could be injurious to the interests of the victims. The Red Cross had therefore to make sure it was not carried away by emotional currents when engaged in an emergency situation.

\section{Strengthening of co-ordination role urged}

A medical action, even in a time of emergency, had to be carefully planned and strictly co-ordinated. In that connection, all concerned were in favour of the strengthening of the ICRC role as a co-ordinator in conflicts and of the League in situations resulting from natural disasters. The Red Cross had to act in a controlled manner corresponding to the needs recognized and the priorities determined by its specialists. Any hasty shipment of medicaments, food, vaccines, equipment, field hospitals and medical teams must be absolutely ruled out in Red Cross activities, for these were often likely to serve political rather than humanitarian purposes, to the detriment of the victims and of the institution.

\section{Well trained personnel}

Emergency medical action, it was pointed out, could not be improvised, so that the personnel provided by National Societies must be well trained. In addition to their technical training, they must be well informed about the Red Cross movement and its principles and about the dangers to be faced. Experience in the field had proved that the members 
of a Red Cross team had to be versatile and be well informed in fields which went beyond their own specialities. The frequently limited number of persons in a team made it impossible to call upon a great number of specialists, and it was therefore essential for a doctor to have some knowledge of epidemiology, hygiene, nutrition and sanitation, and for a surgeon to know the principles of wartime surgery and be able to operate under difficult conditions. In that connection, reference was made to the example of surgical teams on the Kampuchea-Thailand frontier which had to concern themselves with sanitation problems, such as the construction of latrines and the incineration of refuse in the camps. Such problems were unlikely to be encountered by a doctor in his native country.

Several other subjects were discussed during the seminar, for instance: the transfer of sick and wounded people to other countries, tuberculosis treatment, vaccinations, nutrition programmes, etc.

\section{Final recommendations}

In the final plenary session, the participants agreed unanimously on the following recommendations:

a) National Societies wishing to participate in emergency medical actions should develop the preparation of their personnel and material in accordance with the directives of the ICRC and the League.

b) The roles of the ICRC and the League as coordinators of emergency medical actions should be strengthened and the National Societies should not act independently of the established programmes.

c) Emergency medical actions should be planned and directed by experienced professionals. They should be carried out only in relation to the needs of the victims, both in qualitative and quantitative terms.

d) Every National Society should establish a group of experienced professionals responsible for health problems and whose role should not be only consultative but also executive, in the planning and implementation of emergency medical actions.

These recommendations will be discussed at the forthcoming international Red Cross Conference in Manila in November 1981.

A detailed report on the seminar will be published as soon as possible, in the form of a monograph which will serve as a guide to National Societies in training health and medical personnel for emergency actions. 